Claves. Revista de Historia, Vol. 2, $\mathrm{N}^{\mathrm{o}} 3$

Montevideo, Julio-Diciembre 2016

(pp. 163-191) ISSN 2393-6584

\title{
Los intelectuales y la televisión durante la primera década de ese medio en Uruguay
}

Lucía Secco

Universidad de la República

Recibido: 1/10/2016

Aceptado: 6/12/2016

\section{Resumen}

En el período de posguerra, el uso de los medios masivos de comunicación como herramienta para la propaganda bélica generó, entre intelectuales de Estados Unidos y Europa, un rechazo frente a la televisión. En Uruguay, recién en el año 1962 la televisión comienza a tener presencia en medios de prensa y ser objeto del pensamiento intelectuales del país. En este artículo se analizarán las posiciones en relación a la televisión de los periódicos Marcha, Cine, radio, tv, actualidad y El Popular, porque en sus páginas confluyó parte de la intelectualidad del país, aunque cada uno con un perfil y objetivos diferentes.

Palabras Claves: Uruguay - Televisión - Intelectuales -semanario Marcha

\section{Intellectuals and television during the first decade of this medium in Uruguay}

\begin{abstract}
The use of the mass media in war propaganda during the post-war period created, between intellectuals of United States and Europe, a rejection of televisión. In Uruguay, is in 1962 when television start having a presence in the press and to be object of the intellectual thought in the country. In this article, are going to be analize the position around television in the newspapers Marcha, Cine, radio, $t v$, actualidad and El Popular, because in their pages meet part of the intellectuality of
\end{abstract}


the country, but with three different profiles and objectives.

Keywords: Uruguay - Television - Intellectuals - Marcha weekly

\section{Intelectuales y medios masivos}

Durante el período de posguerra, entre los intelectuales se generó un clima de rechazo hacia los medios masivos de comunicación debido al uso de los medios audiovisuales como instrumentos de propaganda por parte de gobiernos totalitarios. En este sentido, textos como los de Clement Greenberg, Vanguardia y Kitsch de 1939 y de Hannah Arendt, Los orígenes del totalitarismo de 1951, ilustran sobre la relación entre cultura de masas y totalitarismo. ${ }^{1}$ Greenberg contrapone la vanguardia con lo kitch, siendo esta última la cultura adoptada por los campesinos que llegan a la ciudad. Es un arte más plano que la gente puede asimilar fácilmente a la vida real, carece de discontinuidad y deja poco espacio para la interpretación o la imaginación. Los gobiernos totalitarios, según Greenberg, utilizan la cultura kitch para dominar a las masas como una herramienta demagógica, como una forma de adular a las masas. Arendt va más allá en su asociación entre la sociedad de masas con el totalitarismo. Para ella el régimen totalitario utiliza el terror no solo para gobernar sino para dominar a las masas hasta en sus actividades más cotidianas. Esto lo logra a través de una sociedad no ya de clases sino de masas, donde las personas están aisladas y son vulnerables.

En el mismo sentido, Dwight MacDonald en su libro Masscult and Midcult, ${ }^{2}$ define a la cultura de masas como una distracción o un narcótico de fácil asimilación. Esto, asegura MacDonald, forma parte de un proceso más amplio de la sociedad industrial que pretende transformar al individuo en parte de una masa. La diferencia con otro tipo de manifestaciones populares es que ésta no proviene del pueblo sino desde arriba. Así, la masscult llega como una forma degradada de alta

1 Ver ARENDT, Hannah, Los orígenes del totalitarismo.,Madrid, Taurus, 1998. GREENBERG, Clement, "Vanguardia y Kitsch" en, Arte y Cultura, Barcelona, Gustavo Gili, 1961.

2 MACDONALD, Dwight, Masscult and midcult. Essays against the American Grain, Nueva York, Da Capo Paperback, 1962. , pp. 4-13 
cultura y se convierte en un instrumento de dominación.

Con la televisión surgen teorías de la comunicación como la de la aguja hipodérmica, que plantean al espectador como un ser pasivo frente al televisor, en donde "cada miembro del público de masas es personal y directamente atacada por el mensaje". 3 Cuando aquí se habla de sociedad de masas se refiere a un grupo homogéneo de individuos que no se conocen y se encuentran aislados. Es este aislamiento el que toma la teoría hipodérmica (al igual que Arendt) para decir que los individuos son indefensos ante el poder de los medios.

Estas teorías llevaron a lo que George Cotkin entienden como una tendencia extendida entre los intelectuales a despreciar y oponerse a estas expresiones populares durante los años de posguerra en Estados Unidos. ${ }^{4} \mathrm{El}$ autor asegura que,

"Para ser un intelectual serio en Estados Unidos era necesario oponerse a las fuerzas traicioneras y niveladoras de la cultura de masas; mostrar demasiado respeto por la cultura de masas (salvo el teatro) podía levantar dudas sobre las credenciales intelectuales. Esa ansiedad en general cegó a los intelectuales de posguerra de la riqueza de la cultura de masas y la cultura popular y obligó a los intelectuales a exagerar la línea que divide la élite de la cultura popular...para muchos intelectuales, sin importar sus posiciones políticas, la cultura de masas parecía ser un enemigo peligroso para la pureza de las ideas intelectuales”.

En relación al discurso crítico sobre los medios desarrollado en América Latina, Mirta Varela en su libro La televisión Criolla explica que

"desde el cuestionamiento económico a los capitales imperialistas que conformaban los consorcios ganadores de las licitaciones de los canales, hasta la publicidad pegajosa tomada como símbolo del consumo más banal y la estupidización del público de masas, la televisión se convertiría en blanco de los ataques de diferentes sectores provenientes del ámbito de la cultura, demostrando, de esta manera, la visibilidad y el poder que había alcanzado". ${ }^{5}$

El objetivo del presente artículo es presentar un acercamiento al pensamiento

3 Charles Wrigth citado por WOLF, Mauro, La investigación de la comunicación de masas. Crítica y perspectivas, Barcelona, Paidós, 1985, p. 25.

${ }_{4}$ COTKIN, George "The tragic predicament: post war american intellectual, Acceptance and Mass Culture", Jeremy JENNINGS, Anthony KEMP WELCH (ed.), Intellectuals in politics. From the Dreyfus affair to Salman Rushdie, Londres, Routledge, 1997, p. 250.

5 VARELA, Mirta, La televisión criolla. Desde sus inicios hasta la llegada del hombre a la Luna, 1951-1969, Buenos Aires, Edhasa, 2005, pp. 
crítico en relación a la televisión durante los primeros años de existencia del medio en el país. Para ello, se van a analizar las posiciones de tres medios de prensa que representan tres orientaciones bien distintas y definidas, donde confluyen diferentes líneas de pensamiento intelectual del país. Por un lado el semanario Marcha, por ser un medio en el que intervino parte de la intelectualidad nacional y que cuenta con un perfil de izquierda independiente, antiimperialista y posicionada a favor del "tercerismo". Por otro lado El Popular, como diario de Partido Comunista y por lo tanto de izquierda pero funcional a un proyecto político. Por último, Cine, radio, tv, actualidad, como un medio donde se replica el discurso proveniente de los canales de televisión.

En este trabajo, cuando se habla de intelectuales, se toma la posición de Jeremy Jennings y Anthony Kemp Welch (1997) para quienes fue la intervención en política por parte de los referentes de las artes, la cultura y la ciencia lo que constituyó la definición del concepto de intelectuales, tomando como referencia el consenso que marca el inicio del uso de la denominación intelectuales a fines del siglo XIX en Francia con el caso Dreyfus, cuando escritores como Émile Zola, André Gide, Marcel Proust y Anatole France buscaron intervenir en la esfera pública de la política para liberar a Alfred Dreyfus, acusado injustamente de traición. De esta forma, se alejan de la definición sociológica que refiere a los intelectuales como aquellos cuya ocupación o profesión está comprometida con lo "intelectual" en oposición al trabajo manual. De esta forma, se tomará al intelectual como aquel perteneciente al ámbito de las artes, la cultura, la ciencia, las universidades, que tienen la intención de intervenir en la esfera política o modificar algún aspecto de la vida social del país. ${ }^{6}$

\section{Repercusiones del nuevo invento}

El primer canal de televisión uruguayo fue el canal 10, que empezó a funcionar en diciembre de 1956. Durante los primeros 5 años, hasta que se instaló canal 4 en 1961 y canal 12 en 1962, la televisión era más bien experimental y no despertaba

6JENNINGS, Jeremy. KEMP WELCH, Anthony, Intelectuales y política: Del caso Dreyfus a Salman Rushdie. Londres, Routledge, 1997, p. 7 
suficiente interés ni del público, ni de los medios, ni de los intelectuales, académicos y personalidades del ámbito de la cultura. El año en que los tres canales privados ya estaban en funcionamiento se da un salto cuantitativo tanto en la venta de televisores como en el interés que los medios presentan sobre la TV. Esto no es algo que se da de forma aislada en nuestro país. Mirta Varela ${ }^{7}$ explica que es en la primera mitad de la década del sesenta cuando se da el salto cuantitativo en los países latinoamericanos que fueron objeto de su estudio. ${ }^{8}$ Para Varela, esto coincide con el boom de la televisión en Estados Unidos y un intento de ese país por insertarse en el mercado de América Latina. En Uruguay este despegue se ve en el aumento de la cantidad de televisores en plaza, que pasó de 6 mil a fines de 1960 a 70 mil en junio de 1962 y 100 mil a fin de ese año. ${ }^{9}$ Para junio de 1963 la cifra se calculaba en 150 mil. ${ }^{10}$

Otra forma en la que se aprecia este boom por la televisión es a través de las repercusiones en la prensa. Los diarios nacionales contaban con páginas dedicadas a la televisión y surgen revistas enfocadas exclusivamente a ese medio, como Canal $T V$ o Platea. Otras revistas que tienen una existencia previa al medio, como Cine, radio, actualidad y Mundo Uruguayo le dedican cada vez más espacio a la televisión. En torno a varios diarios tradicionales, se funda, en 1962, la Asociación de Críticos de Televisión del Uruguay (ACTU) que organiza los premios Ariel a la programación nacional. A su vez, en el año 1962 medios de prensa con otro perfil, como El Popular y Marcha, también se empezaron a interesar por la televisión.

\footnotetext{
7VARELA, Mirta, Op. Cit, pp. 36-44.

8Argentina, Cuba, Brasil, Venezuela y México.

9Mónica Maronna cita el cálculo realizado por Mundo Uruguay, que da un estimado de 30 mil televisores entre 1956 y 1961. MARONNA, Mónica, "La etapa fundacional de la televisión uruguaya". XI Jornadas Interescuelas/Departamentos de Historia. Departamento de Historia.Facultad de Filosofía y Letras. Universidad de Tucumán, San Miguel de Tucumán, 2007.

${ }^{10}$ Datos tomados de artículos publicados en el semanario Marcha en base a estudios de audiencia del Instituto Uruguayo de Opinión Pública. Marcha, Montevideo, 16 de diciembre de 1960, "Presente y futuro de la TV Uruguaya" por Mansilla. Marcha, Montevideo, 13 de abril de 1962, p. 21, "TV”, por M.R.M.. Marcha, Montevideo, 22 de noviembre de 1962, "Arieles para todo el mundo" por M.R.M. Marcha, Montevideo, 18 de agosto de 1963, "Canal 5 frente a la TV comercial. Las telarañas en la pantalla".
} 
Es así que en Uruguay, tal como plantea Mirta Varela para el caso argentino, ${ }^{11}$ el fenómeno de la televisión en los 60 adquirió una magnitud tal que los intelectuales ya no pudieron ignorarlo. Varela, en su artículo Intelectuales y medios de comunicación, ${ }^{12}$ establece tres posiciones adoptadas por los intelectuales frente a la televisión. Una es la de crítica y denuncia al medio. La otra es la de transformación radical y la última es la de generación de alternativas al sistema de medios imperantes. En adelante, veremos las posiciones frente a la televisión adoptadas por intelectuales del semanario Marcha, contrastándolas con las visiones presentes en Cine, radio, tv, actualidad y El Popular.

\section{Réplica del espectáculo televisivo}

Cine, radio, actualidad surge en 1936 como una revista dedicada a la crítica de cine. Por esos años se llamaba simplemente Cine, actualidad y fue fundada por Arturo Despuey y Emilio Dominoni Font. El 5 de setiembre de 1936 la publicación incorpora información sobre radio cambiando su nombre a Cine, radio, actualidad. En 1958 cambia nuevamente a Cine, radio, tv, actualidad. Si bien hay consenso en que esta revista dio origen a la crítica de cine "seria", ${ }^{13}$ para 1962 la sección dedicada al cine era marginal y la televisión ocupaba la primera mitad de la revista, dos páginas de cartelera y casi siempre la tapa.

El perfil principal de la sección de TV de la revista es el de comentar y anunciar los programas de televisión, con énfasis en los nacionales pero con lugar para los programas argentinos y seriales de Estados Unidos. Muchas de estas noticias son sospechosas de tener una intención promocional, ya sea por destacar el logo de la empresa que le da nombre al programa ("Diga By, diga Lo", "Luminarias GESA", "Sala de conciertos Grundig", "Faggilisimo") o por incluir el nombre de la agencia de publicidad que lo produce, como es el caso de "A soñar con Sudamtex", "que

${ }^{11}$ VARELA, Mirta, "Intelectuales y medios de comunicación”, Carlos ALTAMIRANO (Coord.), Historia de los intelectuales en América Latina, Tomo II, Buenos Aires, Katz editores, 2010, p. 760. 12VARELA, “Intelectuales...”, ob.cit.

${ }_{13}^{13}$ Fue considerada una revista pionera en la crítica cinematográfica "seria". Para el crítico Martín Martínez Carril, esta publicación se convirtió "en el mayor medio popular de comunicación, lo que explica la larga vida de la revista". MARTÍNEZ CARRIL, Manuel, "Las generaciones críticas", en Tercer Film, Juan Andrés Bello, director, Gabriel Sosa, editor, $\mathrm{N}^{\circ}$ 1, setiembre-octubre de 2014. pp.5-15. 
cuenta con la supervisión general de Santoro Publicitaria", ${ }_{14}$ o "Las tres tareas de la buena voluntad", "siempre bajo el auspicio de Casa Soler y en promoción publicitaria de Imperio Ltda." ${ }^{15}$ Esto es más notorio si se lee el artículo "Una pujante empresa que hace mucho por la Televisión Uruguaya: Santoro Publicitaria"16 o las notas elogiosas a Gallardo Propaganda. ${ }^{17}$

Las páginas de la revista también destacan figuras de la televisión nacional y extranjera, a través de entrevistas, biografías o sencillamente chismes y novedades de las estrellas. Pinky, animadora argentina que venía semanalmente a Uruguay a conducir shows como "La rueda feliz", "Hoy nos quedamos en casa" o "Buenas tardes teledoce", tiene una presencia constante en la revista. Las fotos de la diva, que ocupan tres cuartas partes de la página, están acompañadas con titulares que anuncian que peligra su actuación en Montevideo, que festeja su cumpleaños en Uruguay o revelan la verdad sobre su enfermedad. Las actrices y conductoras uruguayas como Virginia Luque, María Aurelia Bisutti, Myriam Medina, tienen también su lugar en la publicación, con fotos destacadas y revelaciones sobre su vida amorosa. Otras entrevistas toman a personalidades más fuertes de la TV, como Cristina Morán, José Pedro Voiro, Sarita Otermin, Alejandro Trotta, Héctor Coira o Cacho de la Cruz.

Fuera de los chismes y la farándula, la revista está fuertemente atraída por los aspectos técnicos de la televisión. Esto se ve en notas sobre la altura de la nueva antena de Saeta, la llegada del videotape a canal 4 y canal 12 en 1962 y 1963 respectivamente, los móviles en exteriores, la posibilidad de transmitir eventos emblemáticos de la cultura nacional como el desfile de carnaval o los partidos de fútbol o en la inclusión de artículos dedicados a los técnicos de la televisión. En la cobertura de las elecciones de 1962, por ejemplo, se ve claramente el perfil de la revista. En su artículo "Galardón para Monte Carlo TV: el show de la información de

\footnotetext{
${ }^{14}$ Cine, radio, $t v$, actualidad, Montevideo, 29 de octubre de 1965, "A soñar con Sudamtex...".

${ }^{15}$ Cine, radio, tv, actualidad, Montevideo, 13 de julio de 1962, tapa.

${ }^{16}$ Cine, radio, $t v$, actualidad, Montevideo, 5 de febrero de 1962, p.. 11, "Una pujante empresa que hace mucho por la Televisión Uruguaya: Santoro Publicitaria".

${ }_{17}$ Cine, radio, tv, actualidad, Montevideo, 16 de noviembre de 1962, p. 8. "Oscar Gorking al departamento de TV de Gallard Propaganda”.
} 
las elecciones $1962{ }^{18}$ se destacan los avances de la técnica al servicio de la transmisión del acto, con la computadora IBM, los técnicos de esa empresa y el Instituto Uruguayo de Opinión Pública como las "estrellas principalísimas de este show" que estuvieron "adelantando las informaciones, haciendo conteos y muestreos previos, dando promedios, porcentajes y cálculos de posibilidades”. Está claro que la tecnología no es lo único ni lo más importante. Lo principal es que la tecnología y el esfuerzo estén al servicio del entretenimiento, tal como lo destaca la palabra show en el título del artículo.

Esta mirada frívola de la televisión y las estrellas se intercala con algunas editoriales o artículos que plantean problemas o necesidades del medio, generalmente firmados por Doble Hache. Entre estos temas tratados se puede destacar la polémica por el trabajo de actores uruguayos en argentina, el fomento a la programación nacional y el trabajo de artistas nacionales o el apoyo a programas educativos siempre $\mathrm{y}$ cuando se adapten al lenguaje televisivo $\mathrm{y}$ de entretenimiento. ${ }^{19}$

\section{Marcha y los estudios culturales}

Marcha fue fundada por Carlos Quijano y empezó a salir el 24 de junio de 1939 todos los viernes hasta su clausura en 1974. El semanario asumió un perfil de izquierda independiente, antiimperialista, latinoamericanista y a favor del "tercerismo". En este medio confluyeron los intelectuales de la época como Emir Rodríguez Monegal, Carlos Real de Azúa, Ángel Rama, Homero Alsina Thevenet, Mario Benedetti, Eduardo Galeano, entre otros. En relación a esto, Tulio Halperin Donghi ${ }^{20}$ expresa que Marcha tuvo la capacidad “de constituirse en vehículo de casi todo lo que alcanzaba alguna importancia en la vida intelectual de la nación".

La sección cultural de Marcha estuvo a cargo de Emir Rodríguez Monegal de

${ }^{18}$ Cine, radio, $t v$, actualidad, Montevideo, 30 de noviembre de 1962, pp. 10-11"Galardón para Monte Carlo TV: el show de la información de las elecciones 1962".

${ }^{19}$ Cine, radio, tv, actualidad, Montevideo, 15 de junio de 1962, "Ahora que papá compra el televisor...", por Doble Hache.

${ }^{20}$ HALPERIN DONGHI, Tulio "Apertura”, Mabel MORAÑA, Horacio MACHÍN (ed.), Marcha y América Latina, Pittsburg, Biblioteca de América, 2003, pp. 19 - 20 
1945 a 1959 y de Ángel Rama desde 1959 hasta 1968. En esta sección, las letras y la literatura tuvieron un lugar central y privilegiado. Sus colaboradores fueron intelectuales y profesionales insertos en el espacio de la alta cultura y a través de estas páginas marcaron un canon en la época. Sin embargo, el período iniciado por Rama, si bien mantuvo el lugar de privilegio de las letras, se abrió a otras expresiones artísticas que forman parte de la cultura popular. Para Gustavo Remedi, ${ }^{21}$ esa posición canónica frente a la cultura se agotó para la época en que Marcha dejó de publicarse. Sin embargo, reconoce que algunos intelectuales se adelantaron a ese proceso y comenzaron a acercarse a la cultura popular. Para el autor, lo popular en el semanario se presentó de cuatro formas distintas. Como formas cultas o de vanguardia provenientes de culturas subalternas; en las concesiones a los gustos populares o masivos con temas como el humor, entretenimiento, temas femeninos, radio y televisión; con notas por fuera de la sección cultura que trataban temas sociales o culturales y por último, en lo popular como cultura de masas, alrededor de productos como la música y el cine y en menor medida en torno a la radio y la televisión.

Es así que en este vuelco hacia la cultura popular Marcha empezó a dedicarle, a partir de 1962, una página cada semana a la televisión. En esta página se encuentran varias críticas pequeñas a diferentes programas de televisión nacional y una columna grande que analiza al medio desde una perspectiva social. Si bien los cronistas de televisión fueron varios, la nota central normalmente era firmada por Mauricio R. Miiller o MRM y hacia 1965 el periodista que más se dedica a esa temática fue Danubio Torres Fierro. En estas notas se tocan temas como la publicidad, los doblajes al español, la proliferación de programas extranjeros, los cambios producidos por el videotape, los avances en la transmisión de los partidos de fútbol, la función del crítico de televisión, los programas periodísticos y la política a través de la televisión.

A lo largo de los artículos sobre televisión, se aprecia de forma explícita o implícita la influencia de teóricos de los medios de forma casi simultánea a la

${ }^{21}$ REMEDI, Gustavo. "Blues de un desencuentro" , Mabel MORAÑA, Horacio MACHÍN (ed.), Marcha y América Latina, Pittsburg, Biblioteca de América, 2003, p. 452 
difusión de los textos a nivel regional o mundial, entre los que se encuentran la crítica al libro de Marshall McLuhan aún sin traducción al español o la reseña al libro de Theodor Adorno el mismo año que la Universidad de Córdoba lo editó en español. ${ }^{22}$ Se aprecia también la influencia de otros autores como Dwight MacDonald, al hacer uso del término cultumasas, ${ }^{23}$ como traducción del neologismo masscult. Por otro lado, se perciben similitudes en los temas y enfoques abordados por los estudios culturales ingleses. Abril Trigo ${ }^{24}$ sostiene que, a diferencia de la concepción extendida que dice que los estudios culturales latinoamericanos son un apéndice de los cultural studies ingleses, se pueden ver enfoques similares a los de la escuela de Birmingham en este continente en períodos anteriores y esto se refleja en las páginas culturales de Marcha en la década del $60 . .^{25}$

En este sentido, se ven ciertas coincidencias con artículos de Raymond Willliams, como "Las formas de la televisión", ${ }^{26}$ donde este autor hace un recuento de los géneros en la TV, describiendo aquellos que heredó de otros medios preexistentes. 5 años antes de que se publicara el artículo de Williams, MRM hace un pequeño recorrido por los medios tradicionales y su adaptación a la televisión. El objetivo principal del artículo de $\operatorname{March}^{27}$ es mostrar que no hay nada que haga a la televisión mala de por sí. Los géneros ya existían desde antes. Si bien reconoce que este medio incita a la inercia y la persuasión hipnótica, afirma que "la televisión no es en sí nada; apenas un canal por el que corre todo lo que se le echa adentro".

${ }^{22}$ Marcha Montevideo, 2 de junio de 1967, p. 13, "Mc Luhan: el profeta y su diagnóstico. Viario Trajtenberg". Marcha, Montevideo, 3 de enero de 1967, p. 29, "Sociología, televisión y cultura" por Danubio Torres.

23Marcha, Montevideo, 10 de octubre de 1962, p. 2, "La TV rompe un monopolio" por Mauricio Miiler.

24TRIGO, Abril. "La larga marcha hacia los estudios culturales latinoamericanos", Mabel MORAÑA, Horacio MACHÍN (ed.), Marcha y América Latina, Pittsburg, Biblioteca de América, 2003, p. 381

25Para la autora este proceso tiene su origen en dos eventos: el triunfo del Partido Nacional en 1958 que llevó a la ruptura de Quijano con el Partido Nacional y la revolución cubana de 1959. Aquí se comienza a ver el papel político de la cultura y se pasa de lo literario a lo cultural.

${ }^{26}$ WILLIAMS, Raymond, Televisión. Tecnología y forma cultural, Paidós, Buenos Aires, 2011. 66-104. Este libro, editado por primera vez en 1974 contiene artículos publicados por Williams entre 1968 y 1972 en The Listener, revista semanal de la BBC y a partir de ese año, de sus apreciaciones sobre la televisión de Estados Unidos durante su estadía en la Universidad de Stanford.

${ }_{27}^{27}$ Marcha, Montevideo, 11 de mayo de 1962, p. 24, "Barbas de vecino" por Mauricio Miiler. 
El artículo comienza con un recuento de los géneros televisivos para mostrar que ninguno es privativo de la TV y que los buenos o malos productos culturales que allí se transmiten, existían antes del nuevo medio. Desde los western y las películas policiales frecuentemente criticados en la época, los programas para la mujer que provienen de las revistas femeninas, el teleteatro, que llega del radioteatro y los folletines por entrega o los shows que provienen de los espectáculos de variedades. En octubre de ese año $\mathrm{MRM}^{28}$ retoma esa idea diciendo que las críticas a la televisión en realidad pertenecen a un ente más amplio, la cultura de masas o Cultumasas. Allí se plantea que la gente reacciona con más facilidad contra la TV por el alcance que tiene, pero que los otros medios son "muchísimo más insidiosos".

Estas columnas refleja la posición que tuvo Marcha frente a la televisión en todo el período estudiado. ${ }^{29}$ No busca simplemente comentar e informar sobre las novedades en la programación nacional, pero tampoco es una concesión a la cultura popular tal como lo plantea Remedi. A lo largo de sus columnas sobre televisión Marcha intentará hacer un trabajo crítico de la TV con un espíritu positivo en relación a las potencialidades del medio. Se posicionará en contra del determinismo tecnológico y del desprecio del intelectual a la cultura de masas. La televisión, lejos de ser algo malo de por sí que debía ser rechazado por el intelectual, se transformó en una herramienta potencialmente positiva de educación y extensión de la cultura a amplios sectores sociales a lo que los intelectuales, artistas, medios educativos y sectores de izquierda no alcanzaban con facilidad. Lo que había que modificar, por lo tanto, eran los contenidos y las personas a cargo de estos contenidos. Es por esto que Marcha realizó varios llamados exhortando a los intelectuales a participar del medio.

Desde la primera columna crítica sobre la televisión del 13 de abril de $1962,{ }^{30}$

${ }^{28}$ Marcha, Montevideo, 10 de octubre de 1962, p. 2, "La TV rompe un monopolio" por Mauricio Miiler.

29 Se estudió la primera década de la televisión en Uruguay. Si bien la televisión comenzó a emitirse en 1956, lo hizo el último mes de ese año. Se decidió ampliar la década hasta 1967, dadas las escasas repercusiones del medio durante su primer mes de vida y por la riqueza que brinda incluir las discusiones que se dieron en 1967 entre la televisión estatal y la privada.

30. Marcha, Montevideo, 13 de abril de 1962, p. 21 "TV", por M. R. M. 
Marcha explícita su preocupación por lo que puede y debe llegar a hacer este medio de comunicación de masas en la transformación en la sociedad. El autor de la nota, que realizó una estadía en la BBC y comparó con frecuencia el medio televisivo nacional con el británico, explica que,

"En Inglaterra, el país cuyos ambientes de TV mejor conozco, ya desapareció por completo la vieja superioridad despreciativa hacia la televisión. El estudiado desdén ya no viste ahora, ni social ni internacionalmente. Sin contar por otra parte que la mejor gente, las mejores mentes artísticas y pensantes tienen alguna vinculación de trabajo con el medio".

Se pregunta quiénes y por cuánto tiempo podrán permanecer indiferentes al medio en Montevideo, si habrán programas educativos nacionales, si se mantendrá un lenguaje propio y contenidos que reflejen la sociedad y sus problemas y termina explicando la función y el enfoque que va a tener la sección de TV en Marcha. Miiller anuncia que, "aquí en esta página procuraremos ser observadores atentos del MEDIO, oteando su mejoramiento en favor de la mayoría. Dicen que ya hay cuatrocientos mil ojos uruguayos vigilando". ${ }^{31}$

De la misma forma que niega que la televisión sea un medio eminentemente malo, también niega la teoría de que es el gusto del público medio el que impone el bajo nivel de la programación. Así, en más de una ocasión habla mal del ejecutivo de la TV que reconoce que sus programas son cursis y triviales pero que asegura saber "él por sí mismo, ayudado por dotes de iluminado, que es lo que quiere la gran mayoría”, a lo que agrega "¿que le va Ud. a hacer? La masa quiere eso. No tenemos más remedio que dárselo". A esto el cronista responde que, sin ánimo de idealizar a las masas, tiene signos perceptibles de que "las mayorías ya no son tan desvalidamente estúpidas como algunos especialistas las sueñan". 32

Si el medio televisivo es capaz de transmitir no solo lo peor sino también lo mejor y el público no es ese ser pasivo que solo busca en la televisión el trivial entretenimiento, entonces lo que queda por definir es cuál es la buena programación que puede llegar a transmitir la televisión y quiénes son las personas

31. Marcha, "TV", ob. cit.

32, Marcha, Montevideo, 14 de octubre de 1962, p. 23. "La TV rompe un monopolio", por M. R. Miiller. 
capaces de hacerlo. La función a la que aspira Marcha es la de difusión cultural y educación y quienes deben acercarse al medio para llevar adelante esta tarea son los intelectuales, personalidades del arte y la cultura y el medio educativo.

En el número de fin de año del 62 Miiller explicita el objetivo del trabajo realizado durante todo ese año en el semanario. "Hemos desarrollado un sistema de resistencia en esta tarea regular de croniqueros y observadores de la TV nacional. Resistir, antes que nada, la actitud mental de desdeñosa superioridad de quienes no quieren tener nada que ver con ese medio, porque de esa forma estaría fuera de toda chance de salvación". ${ }^{33}$ En este artículo Marcha es duro con el grupo de intelectuales que mira con desdén a la TV y resalta a la "verdadera élite, la que pesa verdaderamente y es formadora de opinión de mejor seso", la cual mira la televisión "con entendimiento dispuesto; esa élite cuya opinión importa, dice lo suyo y no podemos pasarla por alto”. En el artículo, reafirma la idea de que la televisión es un medio neutral.

"Hay un proceso de abaratamiento tan marcado que uno empieza a sospechar que hubiera algo inherente en la televisión, en el mecanismo o en las circunstancias de la recepción que obligara a la televisión a bajar hasta el ya bajo nivel de la radio. Pues bien, no lo hay". ${ }^{34}$

Más bien, explica, las razones del bajo nivel de la televisión son humanas. "Son sus preconceptos acerca del gusto popular". Más adelante en el artículo se menciona a las personas de la cultura e intelectuales que se acercaron ese año a la TV: Homero Alsina Thevenet, Eduardo Galeano, Carlos María Gutiérrez, Emir Rodríguez Monegal, Guido Castillo, Mario César Fernández, Pablo Mañé Garzón. "Figuras todas que están haciendo alguna que otra aparición esporádica pero que deberían afianzarse en TV porque el medio los necesita y ellos podrían usar bien al medio". ${ }^{35}$ Durante los años siguientes, algunas de las personas mencionadas por Marcha hicieron uso de un espacio estable en televisión, como Eduardo Galeano y Carlos María Gutiérrez. Otros que no fueron mencionados por Marcha también se

33Marcha, Montevideo, 28 de diciembre de 1962, p. 31, "Por una TV sin inhibiciones", por MRM. 34Marcha "Por una TV...", ob. cit. 35Marcha "Por una TV...", ob. cit. 
acercaron al medio en años sucesivos, como Francisco Espínola, Alfredo Zitarrosa o Mario Kaplún. Sin embargo, otros intelectuales y personas de la cultura ya tenían espacio en la televisión desde hacía algunos años. Este es el caso de los actores y directores del teatro. En televisión aparecían periódicamente actores como Taco Larreta, Alberto Candeau, China Zorrilla, Maruja Santullo, Nelly Goitiño y directores como Juan Jones, Elena Zuasti, César Charlone Ortega y Luis Alberto Negro.

La posición de intentar modificar la naturaleza de la televisión con la incorporación de personas de la cultura y la academia que haga otro uso del medio, es algo que Umberto Eco señala dos años más tarde, en 1964, en Apocalípticos e integrados. ${ }^{36}$ Allí el autor explica que la pregunta está mal planteada. No se trata de saber si es bueno o malo que existan medios de comunicación masivos, sino que, dado que no va a ser posible eliminar a los medios, la pregunta debería ser “¿qué acción cultural es posible para hacer que estos medios de masas puedan ser vehículo de valores culturales?". Y agrega que "No es utópico pensar que una intervención cultural pueda modificar la fisonomía de un fenómeno de este tipo".

En su trabajo, ${ }^{37}$ Eco coincide con los apocalípticos en que el problema de la televisión es que está dirigida por grupos económicos que buscan el lucro, por lo cual emiten programas que son los que se estiman de mejor salida. Sin embargo, Eco aclara que en toda industria cultural, a diferencia de otras industrias como la de pasta de dientes, participan personas de la cultura a las que les interesa transmitir ciertos valores culturales más allá del lucro. Es por eso que el alejamiento de los medios por parte de los hombres de la cultura, lo único que hace es empobrecerlos y dejarlos "fuera de toda chance de salvación".

En Marcha, esto es expresado en términos de "ellos" o "nosotros", "buenos" y "enemigos". El 29 de julio de 1966 se explicita que la TV es "un medio de difusión que ha sido ignorado por la "intelligentsia" de este país, dejándola absorber y

${ }_{36 \mathrm{ECO}}$ Umberto Eco, Apocalípticos e integrados,Barcelona, Lumen, 1984, pp. 57-58 37ECO, ob.cit., p. 59 
acaparar por gente que, en la mayoría de los casos, es incompetente". ${ }^{38} \mathrm{El} 2$ de diciembre de ese año, cuando se relata la exitosa transmisión de las elecciones se repite este concepto:

"En cierta forma, también, lo ocurrido puede servir como un desafío a quienes tienen en menos a la televisión, un error bastante difundido en este país. No solamente habla de un poder y posibilidades infinitas, sino que deja la constancia de que, frente a cada aparato receptor, se encuentran innumerables telespectadores que en la actualidad están siendo desperdiciados por la intelligentsia del país. Y, en cambio, educados por el mal camino" ${ }^{39}$

Eco, al mencionar la necesidad de una intervención activa de las comunidades culturales en la comunicación de masas le agrega cierta responsabilidad a estos actores al decir que "el silencio no es protesta, es complicidad; es negarse al compromiso". ${ }^{40}$ Marcha también le achaca la culpa a estas comunidades culturales por el bajo nivel de la televisión. El 31 de diciembre de 1965 el semanario explica que la responsabilidad de la situación de la televisión nacional no es solo de los políticos ni solo "del enajenado pueblo". "Es sobre todo de los intelectuales como clase, formando parte de la enseñanza, del periodismo. Todas las instituciones culturales, todos los intelectuales como individuos, han perdido esta batalla que nunca se dio, que nunca quisieron dar". ${ }^{41}$

El 30 de diciembre de 1966 se publica una mesa redonda ${ }^{42}$ organizada por el semanario bajo el nombre “¿Para qué puede servir la televisión nacional?”. En esta mesa participa Ezra Heymann, Augusto Bonardo y María Carbonell de Grompone moderado por Danubio Torres Fierro. Desde el inicio del debate se deja claro que la televisión puede ser un medio de integración entre lo intelectual y lo popular dadas las posibilidades que este medio tiene como instrumento de difusión cultural. En el copete de la nota, el periodista hace un nuevo llamado a la intelectualidad. "Los que

${ }^{38}$ Marcha, Montevideo, 29 de julio de 1966, p. 26, “Televisión. Buscando un lenguaje”, por Mañé Garzón, P.

39Marcha, Montevideo, 2 de diciembre de 1966, p. 24 "Eficacia redoblada", por Danubio Torres Fierro.

40ECO, ob. cit., p. 61.

${ }^{41}$ Marcha, Montevideo, 31 de diciembre de 1965, p. 21 "Como la TV del Uruguay no hay", por T.B.X. 42Marcha, Montevideo, 30 de diciembre de 1966, segunda sección, pp. 29-31, “¿Para qué puede servir la televisión nacional?”, por Danubio Torres Fierro. 
hacen el complejo cultural del país deben reconocerle el poder como instrumento del siglo XX". Para ello, la gente de la cultura, la enseñanza y la academia debe aprender ese nuevo lenguaje. Bonardo, periodista de televisión argentino que llegó al medio nacional en 1964, hace un fuerte llamado a integrarse a la TV con esperanzas en el poder de la educación, la cultura y el arte para transformar la televisión.

"Ahora bien, o todos a la vez nos damos cuenta de que no hay remedio, de que hay que subir a este vehículo porque si no nos quedamos ahistóricos. O los creadores de cultura, o los herederos de la cultura o los maestros, que son los eternos apóstoles de la verdad revelada, entienden que suben a estos vehículos, o estos vehículos serán prostituidos, inutilizados por lo banal, lo trivial, lo soez, vamos, la nada pero envuelta en celofán. Aquí de lo que se trata es de cargar con lo mejor del ser humano en un vehículo milagroso". ${ }^{43}$

Para Bonardo, es posible que en la televisión aparezcan incluso clases de nivel universitario porque "hasta a los más rebeldes les seduce la cultura". Pero primero los docentes, intelectuales o actores culturales deben conocer la herramienta y aprender a seducir a la hora de enviar sus mensajes por este medio masivo. La Universidad, dice más adelante, no debe dar clases al más alto nivel. Ese tipo de clases se dan en el aula. Una conferencia de dos horas puede que haya que reducirla a 10 minutos si se la traslada a la TV. Pero, aclara, esto vale la pena "por la multitud de auditores, por lo fecundo de la siembra".

En ese mismo número, Danubio Torres explica sus preocupaciones sobre el estado actual de la televisión y los efectos que, dejar al medio tal cual esta, genera en los individuos y la sociedad.

\footnotetext{
"Porque todo cuanto se hace en TV tiene un único fin: el disimulo de la verdad, fomentando el conformismo. Esa tendencia, que es un verdadero adoctrinamiento diario, lleva al público a mantenerse tranquilo, con la imagen de un Uruguay edénico, donde todos estamos en paz y prosperidad, sin incitarle a la lucidez, a la toma de conciencia, a la visión clara de lo que nos ocurre". ${ }^{44}$.
}

43Marcha, “¿Para qué puede servir...”, ob. cit.

44Marcha, Montevideo, 30 de diciembre de 1966, segunda sección, p. 31, “Concentración de poder en la TV", Danubio Torres Fierro. 
Aquí el autor del artículo de Marcha cita el texto Televisión y cultura de masas, ${ }^{45}$ en el cuál Theodor Adorno estudia el efecto de la televisión en la personalidad del espectador. Luego, en esa misma nota Torres explica el verdadero problema político producido por el estado de la televisión en Uruguay. En un contexto político como el de 1966 en el que, como dice el periodista, "importa la toma de conciencia y mirar hacia la realidad", en nada ayuda tener a miles de espectadores en la inacción y el conformismo. Esto empeora cuando se ve que se trata en su mayoría de la clase media. El pensamiento intelectual de izquierda, debe estar dirigido a esa misma clase que ahora está siendo alienada por la televisión. Cita aquí a Jean Paul Sartre, ${ }^{46}$ para preguntar

“¿A quién queremos convencer? ¿A las clases que ya están en lucha contra el capitalismo y que ya están convencidas (con o sin crímenes) de la necesidad de combatir hasta el fin contra el imperialismo o a ese vasto sector de la clase media que en este momento está vacilante? Es a las masas pequeño burguesas a las que tenemos actualmente que despertar y sacudir, porque su alianza con la clase obrera -incluso en lo interno- es deseable".

La nota culmina con un llamado a la responsabilidad de quienes hacen televisión, para poder construir una ideología democrática. La posición de Marcha resulta aquí clara. La televisión, con una audiencia de un millón de personas para 1967, que no habían sido alcanzadas por ningún otro medio antes, genera efectos o influencias en el espectador. Si los intelectuales, círculos culturales o pensadores de izquierda se acercaran a la televisión, llegarían a ese millón de personas para aportar en su desarrollo educativo y cultural y generar un pensamiento de acuerdo a una ideología de izquierda. De no hacerlo, ese público quedará expuesto a las ideologías de programas extranjeros, las empresas comerciales que buscan mantener el statu quo o la parcialidad del gobierno. No eran momentos para dejar a todas esas

45El artículo fue publicado por primera vez en 1964 en la revista Querterley of film, radio and televisión. Vol. 8. El mismo año del artículo de Marcha, 1966 fue editado en español por la Escuela Universitaria de Córdoba. Adorno analiza los contenidos televisivos desde un punto de vista psicológico. En su estudio de las ficciones televisivas explica que el conflicto entre individualismo y sociedad se resuelve siempre de la misma forma, quedando todo en un status quo. El conflicto, es puro simulacro.

${ }^{46}$ La cita es del libro Ideología y cambios sociales editado también durante ese año por Editorial Alfa. 
personas en manos de agentes que fomenten el quietismo y la apatía.

\section{Junto a los trabajadores}

El Popular fue el diario oficial del Partido Comunista del Uruguay, fundado el 1 de febrero de 1957. Surge para sustituir al diario Justicia, órgano oficial del PCU que dejó de publicarse a fines de 1956. Este cambio es consecuencia de las transformación que se dieron en la interna del Partido en julio de 1955 tras la destitución de Eugenio Gómez de la dirección del PCU. Este "golpe" como lo denomina Gerardo Leibner, fue planificado y llevado adelante por un grupo de dirigentes encabezado por Rodney Arismendi y José Luis Massera. ${ }^{47}$ La nueva dirección del Partido se orientó a generar un movimiento de masas que aglutine a los sectores trabajadores, urbanos y trabajadores rurales. Arismendi expresaba que los planteamientos debían ser "accesibles a las grandes masas", partiendo de reivindicaciones sentidas por los sectores populares, y a partir de allí ir incorporando otros planteos y reivindicaciones orientadas a los intereses programáticos del Partido. ${ }^{48}$ Esta estrategia, exitosa según la visión de Leibner, posibilitó que en la década del 60 y 70 el PCU tuviera un amplio alcance popular entre obreros, trabajadores y estudiantes.

En este contexto, el pasaje de Justicia a El Popular refleja este cambio de orientación del Partido. Mientras que el primero era el órgano oficial del Partido Comunista, El Popular pretendía ser un diario con intereses en el mundo exterior, sin dejar de expresar la línea del Partido. Para Leibner, El Popular antes de ser un diario del Partido debía ser un diario que cumpliera las necesidades de información de un público amplio y no solo los afiliados y simpatizantes del PCU. ${ }^{49}$ Es por eso que en sus páginas se incorporaron secciones de información nacional e internacional, con un fuerte énfasis en los planteos sindicales. Pero también se dedicó un espacio fijo de una o dos páginas al deporte (fútbol pero también otros como carreras de caballos), así como la cartelera de espectáculos, lista de farmacias

\footnotetext{
47 LEIBNER, Gerardo, Camaradas y compañeros. Una historia política y social del Partido Comunista del Uruguay, Montevideo, Trilce, 2011, p. 227

48LEIBNER, op. cit,, p. 247

49LEIBNER, op. cit, P. 286
} 
de turno y otras informaciones de interés general. Esto se debe a que desde el viraje de 1955 tanto El Popular como el PCU buscaban acortar las distancias con los hábitos y sensibilidades de los sectores populares a quienes se pretendía influir, intentando adaptarse a los lenguajes y los hábitos de las clases que se quería atraer.

El espacio destinado a la televisión fue, en gran medida, una concesión al gusto popular, una forma de ofrecer información de interés para los sectores populares, aunque también se utilizó el espacio para realizar reivindicaciones sindicales o para hablar sobre los espacios televisivos destinados al Partido. A mediados del año 1962, El Popular incorpora la programación de los tres canales existentes hasta el momento, aunque en un principio, con un carácter muy inestable, ya que su aparición dependía del espacio libre en la edición, llegando a omitirse alguno de los tres canales o la columna entera. Más allá de esa pequeña mención a la programación, la televisión no ocupó mucho espacio en las páginas del diario. Sin embargo, se publicaron tres notas ese año que son significativas por plantear las posiciones en relación a la televisión, que el periódico mantuvo a lo largo de los años.

La primera de ellas es quizás la nota que explicita de forma más contundente una posición política de El Popular sobre la televisión y sus potencialidades. Titulada "TV en el Uruguay. Algunas apreciaciones", la nota fue publicada el 3 de febrero de 1962. ${ }^{50}$ Este artículo comienza expresando que el nuevo elemento expresivo que ha revolucionado la forma de difusión y entretenimiento, no está al alcance de todos. $\mathrm{El}$ alto costo de los aparatos impide que los trabajadores pueda tener un receptor de TV, perteneciendo, los que disfrutan del medio, a la clase media y la alta burguesía. Esto, explica el artículo, es lo que genera el nivel actual de la TV. En una mirada similar a la planteada por Marcha, se sostiene que el medio no es en sí mediocre, que tiene altas posibilidades, pero es el hecho de estar manejada por la alta burguesía y al servicio de la misma que adquiere ese nivel.

"La TV es en este momento fiel reflejo de la clase a que sirve. Pero la TV no lleva en sí misma este elemento regresivo hoy imperante. Puede y debe cumplir importantes

5oDesde 1 de enero de 1962 hasta 31 de diciembre de 1967 
cambios en una sociedad de desarrollo avanzado, en su labor informativa que, si es encarada con la seriedad necesaria constituye un vínculo importante de unión con los demás pueblos a través del conocimiento imparcial y objetivo del desarrollo de los movimientos sociales del mundo. Pero la labor para la que la TV está fundamentalmente capacitada -por su aparato técnico de difusión- es el enriquecimiento cultural del pueblo que bajo diferentes aspectos puede contribuir a este desarrollo, desde el punto de vista de la enseñanza, por ejemplo...”.

El artículo continúa mencionando ejemplos de ese tipo de uso en los países socialistas, Gran Bretaña o Francia y agrega que es útil no solo para el desarrollo de la educación sino también de la difusión de las artes (expresiones de la alta cultura, en este caso). Sigue diciendo que los problemas de la televisión no se dan por una característica del medio sino por la dirección que le imprimen quienes lo controlan: "En Uruguay son dos familias de la alta burguesía manteniendo en la TV un régimen retrógrado y materialista tan característico de su clase...”. Y finaliza de esta forma el planteo:

"No nos sorprende, pues, que la TV sea hoy uno de los centros de la reacción y el anti-fidelismo, pero los tiempos pasan. Las revoluciones no pueden ser detenidas por fantoches y el día llegará en que el obrero pueda ver en su hogar y no solamente en los escaparates de las grandes tiendas”.

Este planteo tiene ciertas similitudes con el de Marcha, en el sentido de que rechaza el determinismo tecnológico y rescata el poder que tiene el medio para difusión cultural y educativa. En este caso, quienes deben tener el control de la producción televisiva no son necesariamente intelectuales pero sí la clase obrera o una clase que ponga al medio en beneficio del proletariado. La televisión debe ser objeto de una planificación política de forma tal que, mediante la enseñanza y la difusión de la cultura, aporte al desarrollo del país. A diferencia de lo que sucedió en Marcha, sin embargo, este planteo no se va a repetir en futuras ediciones. Sin embargo, el artículo menciona un aspecto que sí se retomará a lo largo de los años y será el centro de preocupación de El Popular en relación a este tema: el trabajador del medio. Denuncia aquí a la TV como un lugar sin regulación donde la única forma de ascender es pisando a los de abajo.

El 27 de setiembre se retoma este tema que va a ser la cabecilla de batalla del 
diario. ${ }^{51}$ La nota surge a partir de un comunicado que dio la Federación Uruguay de Espectáculo Público el 3 de ese mes sobre la televisión nacional. Allí se plantean el problema de la programación a base de videotapes, provenientes fundamentalmente de Argentina y Estados Unidos que reduce el trabajo nacional y suprime todo elemento cultural propio dejándonos sujetos a los valores culturales foráneos. En relación a esto último, el artículo destaca el "Carácter deformante que tiene la TV como vehículo de difusión, para todo aquel que no posee los elementos culturales que lo defiendan”. Junto a otros medios masivos como el cine o el cómic, la televisión se transforma en un "complejo de esterilización cultural y distorsionador de conciencias". En relación al aspecto laboral, se reclaman los sueldos bajos de los artistas y técnicos a la vez que se denuncia que los tapes no pagan impuestos, favoreciendo el enriquecimiento de los propietarios de las emisoras. La tercera nota de ese año, "Excluidos de la TV"52 denuncia que los canales invitaron a representantes de todos los partidos políticos salvo al Frente Izquierda de Liberación (FIDEL), por ser los canales un monopolio en manos de la clase dominante para quienes el FIDEL representa una amenaza.

A fines de 1963 a la cartelera se le agrega una sección llamada "Pantalla chica" firmada por VIDEON con noticias sobre programas o canales de televisión. Esta sección tampoco sale todos los números, limitándose a tres apariciones durante 1963. Un año más tarde la sección se amplía. Pasa a llamarse "Telenoticias”, la firma R.N. y contiene además de la cartelera diaria, los programas recomendados del día, "Qué se dice" con breves novedades o chismes sobre los programas y figuras de la televisión y una o dos notas destacadas. Aquí la frecuencia es diaria, aunque muchas veces la sección puede verse reducida a la cartelera y los recomendados.

En general, se comentan programas y se brindan novedades sobre los canales, la programación o estrellas de la TV nacional o extranjera. Más que un espacio de denuncia, análisis, crítica social al medio o espacio donde plantear alternativas al sistema actual, la columna es un espacio para complacer los gustos de los lectores.

${ }^{51}$ El Popular, Montevideo, 27 de setiembre de 1962, p. 4, "T.V. Acuciante realidad de explotación y ataque a la cultura”, por O.I.

52El Popular, Montevideo, 14 de noviembre de 1962", p. 4, "Excluidos de la TV". 
Sin embargo, ese aspecto predominante de la televisión, como concesión al gusto popular y entretenimiento, convive en la propia sección "Telenoticias" o en otras páginas del diario, con notas esporádicas que tratan los temas abordados en el año 1962. Uno de ellos está constituido por las denuncias sobre la discriminación contra el FIDEL o la reproducción de las apariciones de dirigentes del FIDEL en programas de televisión. El otro aspecto, más abordado aún, es la denuncia por la situación de los trabajadores y reclamo por trabajo nacional. El Popular seguirá muy de cerca los reclamos de la Federación Uruguay de Trabajadores de Espectáculos Públicos (FUTEP), el Movimiento Unificado de Trabajadores de Radio y Televisión, la Sociedad Uruguaya de Actores (SUA) y la Federación Uruguaya de Teatro Independiente (FUTI) .

En ambos temas se suele tocar el problema de fondo, que es la administración de las ondas del Estado por parte de grupos empresariales y de poder, que no buscan el beneficio de la colectividad sino el suyo propio. Un ejemplo está dado por la nota editorial del 12 de junio de 1965 donde se denuncia la falta de espacio que partidos de izquierda y organizaciones sindicales tienen en la televisión. All ${ }^{53}$ se reitera que los medios masivos constituyen un monopolio en manos de personas que "se identifican con los intereses de gobierno y de las clases dominantes, y que traban por todos los medios el acceso a ellas de los partidos de la izquierda y del movimiento sindical clasista".

En relación al segundo tema, se va a reclamar más espacio para el trabajador local del medio, que no solo recibe salarios bajos sino que se encuentra cada vez más excluido de la televisión ante la llegada de los videotapes. Los dueños de los canales no pagan impuestos por la importación de programas extranjeros, y se enriquecen de esa forma, a costa del desempleo del artista nacional. Este no es un problema únicamente sindical sino cultural. Los empresarios no usan las ondas del Estado para cumplir su función cultural, sino que dejan de lado la expresión nacional en beneficio de un "colonialismo cultural". Esto derivó en el apoyo del canal a la "ley de

53El Popular, Montevideo, 12 de junio de 1965, p. 4, "Acceso a la radio y la TV”. 
trabajo de radio y televisión" promovida por FUTEP en $1963 .{ }^{54}$ En las notas sobre la propuesta de ley se vuelve sobre los tópicos de la necesidad de programación nacional y la responsabilidad de los canales de televisión de emitir programas educativos y culturales en miras al desarrollo del país. Aquí se inicia, por otro lado, un enfrentamiento con la Asociación de Broadscaster del Uruguay (ANDEBU), bajo la dirección de Justino Jiménez de Archeága, la cual se declara en contra de toda regulación alegando el ataque a la libertad de expresión. El enfrentamiento con esta asociación se hará más intensa en 1966 y 1967 cuando canal 5 empieza a transmitir publicidad privada.

\section{El desencanto de la alternativa estatal}

En estos planteos, se muestran las posiciones de los diferentes medios ante los canales privados de televisión, pero ¿̇cuáles fueron las posiciones adoptadas por estos medios frente a la televisión estatal?. Para el semanario Marcha, hasta 1963, la alternativa a la situación de la TV en Uruguay estuvo puesta en la llegada del canal del SODRE. Desde que el canal oficial era un proyecto, Marcha anunciaba los avances del mismo aclarando que el Estado no debía pensar en el lucro sino en la calidad artística. ${ }^{55}$ Tenía que ser un medio de difusión de la cultura, pero no una cultura solemne dirigida a la élite, sino a las grandes mayorías. "Se trata de hacerla no sólo digerible sino también paladeable para una audiencia inmensa y nueva". ${ }^{56}$

Esta expectativa generada desde 1955, año en que llegan a aduana los equipos de transmisión de televisión adquiridos por el SODRE, se convierte, para el semanario, rápidamente en decepción. Apenas iniciadas las emisiones experimentales en canal 5 con 2 horas por día de transmisión, Marcha se pregunta “¿Qué pasa con SODRE Canal 5 ? Nada de particular; mejor dicho, ahora que se produjo la largada en este mes de abril, la actividad parece aferrada al mantenimiento de un pobre estatus

54El Popular de los viernes, Montevideo, 8 de noviembre de 1963, p. 29 “¿Por qué es necesaria una ley que regule la radio y la TV? Nota I”, por Carlos Bonavita. y Eduardo Prous y El Popular de los viernes, Montevideo, 29 de noviembre de 1963, p. 4, "¿Por qué es necesaria una ley que regule la radio y la TV? Nota II”, por Carlos Bonavita y Eduardo Prous.

55 Marcha, Montevideo, 21 de junio de 1957, p. 4 "T.V. Con impuestos".

${ }_{56}^{6}$ Marcha, Montevideo, 20 de julio de 1962, p. 20, "El gran cuco. De los clásicos a la cultura”, por M.R.M. 
quo", ${ }^{57}$ alegando que solo se emiten películas de la cineteca y documentales de las embajadas. En junio de 1963, cuando se inician las emisiones regulares por Canal 5, Eduardo Galeano escribe una nota lapidaria. ${ }^{58}$ Comienza narrando todas las expectativas puestas en ese canal, para luego explicar el desencanto:

"en este corto tiempo transcurrido la TV oficial ha defraudado esa expectativa, en buena medida porque carece de recursos para funcionar como debiera y en buena medida, también porque nuestros engranajes burocráticos son tan pero tan eficaces en la ardua tarea de generar aburrimiento, que ya se puede hablar de rutina a propósito de una experiencia que está dando sus primeros pasos".

Hacia el final, la nota sentencia que la televisión nacional está condenada a vegetar. Sin embargo, no todas son críticas a la TV pública. Se publican artículos elogiosos sobre algunos programas culturales y también se formulan propuestas de programas educativos o documentales sobre la realidad nacional a los que, según el semanario debería abocarse el Canal 5. Quizás la razón de ser tan críticos con ese canal se explica en la copete de la nota del 4 de octubre de 1963 dedicada a un recital de la srta. Kaussenbaum transmitido por Canal 5,

"Porque te quiero te critico. A nadie se le ocurriría hacer una crítica estilística a los canales comerciales, pero el SODRE representa una esperanza demasiado larga y cara como para dejar pasar un error de concepto como el que quiero señalarle”. ${ }^{59}$.

El Popular se sitúa en la vereda opuesta al realizar un apoyo constante y sostenido a la programación del Canal 5, por ser éste el único que transmite programación cultural y educativa para la audiencia masiva. Así, los contenidos de este canal van a ser los que más integren los "Recomendados" o las reseñas de programas de la sección.

El panorama, sin embargo, cambia un poco a partir de los problemas que el canal del SODRE tiene con ANDEBU, cuando el primero empieza a emitir publicidad privada en 1966. Un primer conflicto se dio con la ley de presupuesto de 1964, que

57Marcha, Montevideo, 26 de abril de 1963, p. 23, “Temporada TV, 1963", por M.R.M. ${ }^{5}{ }^{2}$ Marcha, Montevideo, 23 de agosto de 1963, p. 19, "El Canal 5 frente a la TV comercial. Las telarañas en la pantalla”, por Eduardo Galeano.

59Marcha, Montevideo, 4 de octubre de 1963, p. 22 “TV. Cultura popular sin soda”. 
establecía que el 20\% de la publicidad oficial de todos los organismos del Estado debían destinarse a las radioemisoras del SODRE. En 1966 la Comisión Directiva redobla su apuesta con la resolución $\mathrm{N}^{0} 41.511$ donde anuncia que comenzará a incluir publicidad privada en su programación. ANDEBU inició de inmediato una campaña en contra de esta medida alegando competencia desleal, ilegalidad e incluso inconstitucionalidad. ${ }^{60} \mathrm{El} 23$ de marzo envió al SODRE un recurso de revocación de la medida fundamentando que no existe base legal para ello. Al mismo tiempo, envió un una denuncia por ilegalidad al Consejo de Gobierno, inició una campaña internacional al plantear el tema en la Asociación Interamericana de Radiodifusión realizada en Buenos Aires en junio de 1967, y difundió su punto de vista a través de todos los medios asociados a ANDEBU a nivel nacional.

En Canal 5, por su parte, renunció la Comisión Directiva del SODRE que había decidido incorporar la publicidad privada. Si bien aquella medida contó con la simpatía del Ministro de Educación y Cultura Luis Hierro Gambardella y de la justicia ${ }^{61}$ fue claro un intento por parte de la nueva Comisión Directiva de "hacerle el juego a ANDEBU"62 y tomar medidas para desmantelar al canal oficial. Esto se ve con la suspensión de ciclos culturales exitosos, como "La gente", "Nuestra gente y nuestro tiempo", y "Francisco Espínola nos acerca a los clásicos". Este último consistía en un análisis de los clásicos de la literatura universal, que se emitía tres veces por semana. Espínola realizaba las emisiones de forma gratuita y según sus declaraciones, "hablaba para que a Cervantes lo entendieran hasta los rancheros de mi país". ${ }^{63}$ La arbitrariedad de esta medida provocó fuertes repercusiones en Marcha y El Popular. ${ }^{64}$ Éste último medio realizó un seguimiento del movimiento

6oFARAONE, Roque, Estado y TV en el Uruguay, Montevideo, Fundación de Cultura Universitaria, 1989.

61Ver, Brecha, Montevideo, 28 de junio de 2013, "Los inicios de TNU a 50 años de su fundación. En blanco y negro, por Florencia Soria, pp. 8 y 9.

${ }^{62}$ Marcha, Carta de los lectores, Montevideo, 2 de setiembre de 1967, p. 02, “¿Con Canal 5 o con ANDEBU?”, por Horacio Rebufell.

${ }_{63}$ El Popular, Montevideo, 5 de octubre de 1967, p. 14, "Arbitrariedad en Canal 5. Suprimen el programa del escritor Paco Espínola".

64Marcha, Montevideo, 20 de octubre de 1967, pp. 30-31, "Francisco Espínola nos acercaba los clásicos. La lección del maestro". El Popular, Montevideo, 15 de octubre de 1967, p. 6, "Solidaridad con Paco Espínola". El Popular, Montevideo, 18 de octubre de 1967, p. 4, "Solidaridad con Paco Espínola".El Popular, Montevideo, 24 de octubre de 1967, p. 4 "Mañana es el homenaje a Paco 
en solidaridad a Paco Espínola, integrada por numerosas personalidades de la cultura. Además, el diario denunció que esta medida era parte de una campaña oculta de ANDEBU para silenciar y privatizar al Canal 5. Esto, según el diario, no respondía a razones empresariales sino de la más alta política. ${ }^{65}$

La Comisión Directiva no dio razones al levantar el programa de Espínola, pero dejó entrever la omnipotencia del poder que ejercen los medios privados de comunicación. En el número de fin de año de 1967 de Marcha, Danubio Fierro inicia la nota ${ }^{66}$ diciendo que si bien el año pasado se insistió en los peligros que los usos de la televisión pueden generar en el medio, este año se debe insistir en el problema

“...de la colonización cultural y el intolerable magisterio que detentan sobre los medios de información algunos grupos de verdadero poder económico y político, con ambiciones muy concretas, que no coinciden precisamente con las necesidades más inmediatas de la hora actual. Se trata, nada más y nada menos, que de un problema de control cultural".

El cronista constata en esta nota que, en un país que tiene muestras de "talentos e inteligencias despiertas", la televisión "está copada por los mediocres" para decir cada día los mismos lugares comunes. A esto se añade el poder de la publicidad "que opera con sutileza en la transmisión de valores", y busca que el público "reciba un mensaje conformista y estereotipado, que lo identifique con el status quo y no le exija reflexión". La nota termina coincidiendo con el punto de vista de El Popular. Para el periodista, mientras no se lleve adelante una ley de televisión, "la TV seguirá moviéndose dentro del mismo círculo vicioso que hasta ahora". ${ }^{67}$

Espínola".El Popular, Montevideo, 25 de octubre de 1967, p. 6, "Hoy miércoles 19:30 en teatro Odeón, gran homenaje a Paco Espínola".El Popular, Montevideo, 28 de octubre de 1967, p.4, "La solidaridad del Frente iIzquierda con Paco Espínola".

65El Popular, Montevideo, 19 de octubre de 1967, p. 4, "Lo que se esconde tras el agravio a "Paco" Espínola”.

${ }^{66}$ Marcha, Montevideo, 29 de diciembre de 1967, “TV y grupos de presión”, por Danubio Torres Fierro.

${ }_{67}$ Marcha, "TV y grupos de presión", ob. cit. 


\section{Conclusiones}

Ninguno de los tres periódicos optó por el desprecio a la televisión como medio, pero tampoco por la transformación radical. Cine, radio, $t v$, actualidad tomó una actitud más bien de entusiasmo en relación al medio y réplica del discurso de los canales de TV, mientras que El Popular y Marcha plantearon, en el mejor de los casos, alternativas al medio. El Popular incorporó un espacio a la televisión fundamentalmente como parte de una política general del medio de incluir información que resulte de interés a un amplio sector de lectores, como forma de atraer a grandes grupos al proyecto partidario. Por otro lado, el diario mencionó a la TV para denunciar la poca presencia del Partido en la pantalla o para difundir sus apariciones en el medio. Finalmente, como parte de una política general de $E l$ Popular de apoyar y difundir los reclamos sindicales, la sección de TV replicó los reclamos de los trabajadores del medio, defendió el trabajo y la producción de programación nacional y criticó la colonización extranjera en la pantalla. La búsqueda de una alternativa, para El Popular, estuvo puesta justamente en la regulación del medio que asegure la presencia de productos culturales nacionales en las pantallas de TV y por lo tanto proporcione puestos de trabajo nacionales.

Marcha por su parte, buscó el cambio en la integración de intelectuales de izquierda y actores de la cultura que modificaran el uso que se le hace a la televisión. Para el semanario, el medio televisivo no es bueno o malo de por sí, sino que depende del tipo de programación. Esta debía orientarse, según Marcha, en la difusión cultural y educativa para elevar el nivel cultural de la población. Para ello, debían integrarse los intelectuales al quehacer televisivo y el canal oficial debía estar orientado a difundir este tipo de programación.

En relación al acercamiento de los intelectuales y la televisión, las críticas de Marcha a las posiciones elitistas de ciertos intelectuales que rechazan o desdeñan el medio, nos muestra que en Uruguay de la década del 60 existía un sector de la intelectualidad, educadores y artistas que rechazaban o ignoraban a ese medio masivo de comunicación. Dicha posición, que coincide con críticas a nivel mundial contra la cultura masiva en general y a la televisión en particular, no está 
desarrollada en este artículo, siendo solo aludida por el hecho de que Marcha la rechaza en reiteradas oportunidades y podrá ser objeto de otros estudios posteriores. Las posiciones que se ven reflejadas en este estudio son las de intelectuales de izquierda que tienen confianza en la televisión como medio de difusión de ideas y como vehículo para elevar el nivel cultural y educativo de una amplia cantidad de la población nacional, que para la época poseían aparatos de televisión.

\section{Bibliografía}

ADORNO, Theodor, Televisión y cultura de masas, Eudecor, Córdoba, Escuela Universitaria de Córdoba, 1966.

ARENDT, Hannah, Los orígenes del totalitarismo.,Madrid, Taurus, 1998.

COTKIN, George "The tragic predicament: post war american intellectual, Acceptance and Mass Cultre", Jeremy JENNINGS, Anthony KEMP WELCH (ed.), Intellectuals in politics. From the Dreyfus affair to Salman Rushdie, Londres, Routledge, 1997, p. 250.

ECO, Umberto, Apocalípticos e integrados. Barcelona, Lumen, 1984.

FARAONE, Roque, Estado y TV en el Uruguay, Montevideo, Fundación de Cultura Universitaria,1989.

GREENBERG, Clement, "Vanguardia y Kitsch" en, Arte y Cultura, Barcelona, Gustavo Gili, 1961.

JENNINGS, Jeremy; KEMP WELCH, Anthony, Intelectuales y política: Del caso Dreyfus a Salman Rushdie, Londres, Routledge, 1997.

LEIBNER, Gerardo, Camaradas y compañeros. Una historia política y social del Partido Comunista del Uruguay, Montevideo, Trilce, 2011.

MACDONALD, Dwight, Masscult and midcult. Essays against the American Grain, Nueva York, Da Capo Paperback, 1962.

MARAÑA, Mabel; MACHÍN, Horacio (ed.), Marcha y América Latina, Pittsburg, Universidad de Pittsburg, 2003.

VARELA, Mirta. "Intelectuales y medios de comunicación” En Altamirano, Carlos (Coord.), Historia de los intelectuales en América Latina, Tomo II, Buenos Aires, Katz editores, 2010. 
VARELA, Mirta, La televisión criolla. Desde sus inicios hasta la llegada del hombre a la Luna, 1951-1969, Buenos Aires, Edhasa, 2005.

WILLIAMS, Raymond, Televisión. Tecnología y forma cultural, Paidós, Buenos Aires, 2011.

WOLF, Mauro, La investigación de la Comunicación de Masas. Crítica y perspectivas, Barcelona, Paidós, 1987. 